\title{
Sobre el legado de Paulo Freire
}

\section{Diego Barboza DOI: https://doi.org/10.46681/Temas/a2021n7a2}

\begin{abstract}
Antes que nada reconocemos que sentir miedo es manifestación de que estamos vivos. No tengo que esconder mis temores. Pero lo que no puedo permitir es que mi miedo me paralice. Si estoy seguro de mi sueño político, debo continuar mi lucha con tácticas q ue disminuyan el riesgo que corro. (Freire, 1993, p. 64).
\end{abstract}

\section{Resumen}

El presente artículo es un homenaje a Paulo Freire a cien años de su nacimiento. Busca recuperar de su obra el concepto de relaciones educativas, despojándolo de miradas ideologizantes. Mediante este ejercicio y con la inclusión de algunas breves referencias a experiencias del autor de este trabajo en su tránsito por diferentes espacios educativos, se propone una reflexión sobre la condición de educadores y educadoras, siempre en relación y atravesada por la dimensión política. Así, se presenta a Paulo Freire en su estado más básico, más sustancial, como un ser humano más allá de las interpretaciones ya conocidas sobre su producción, y se boceta una memoria de un Freire atemporal. El artículo es, también, una invitación a repensar el propósito, el lugar y el significado que como sociedades aún modernas asignamos a las instituciones educativas, y el que deseamos asignarles en el contexto de los procesos y proyectos de transformación social.

Palabras clave: Paulo Freire, relaciones educativas, condición de educador/a, transformación social, educación integral.

\begin{abstract}
This article is a tribute to Paulo Freire one hundred years after his birth. It seeks to recover from his work the concept of educational relations, stripping it of ideologizing views. Through this exercise and with the inclusion of some brief references to experiences of the author of this work in his transit through different educational spaces, a reflection is proposed on the condition of educators, always in relation and crossed by the political dimension. Thus, Paulo Freire is presented in his most basic, substantial state, as a human being beyond the already known interpretations of his production, and a memory of a timeless Freire is sketched. The article is also an invitation to rethink

\footnotetext{
${ }^{1}$ Maestro de Escuela Común (IINN-ANEP). Magíster en Gestión Educativa (Universidad ORT Uruguay). Sub-Director de Escuela urbana de Montevideo, Uruguay (DGEIP-ANEP). Docente de Pedagogía (IFD Trinidad-Flores-CFE-ANEP).
} 
the purpose, place and meaning that we as still modern societies assign to educational institutions, and that which we wish to assign to them in the context of processes and projects of social transformation.

Keywords: Paulo Freire, educational relations, educator condition, social transformation, integral education.

\section{Nota primera}

Este artículo tiene tres destinatarios directos, más allá de todas aquellas y todos aquellos que se den la posibilidad de leerlo. El primer destinatario soy yo mismo, deviniendo y construyéndome una y otra vez. Los segundos destinatarios son todos los maestros y maestras con quienes me he ido cruzando y que han tenido no solo la valentía sino también la humildad de aceptarme tal cual voy siendo, aceptarme incluso en los momentos más duros y más intolerantes de mi vida, cuando el dogmatismo lo opacaba todo y mis miedos emergían como soberbia que intenta ocultar. Por último, está dirigido a todas y todos los que hoy deciden transitar una formación que los convierta en educadoras y educadores, a ellas y ellos les dedico este tiempo y lo dedico a través de quienes hoy forman parte de una pequeña comunidad de aprendizaje en un instituto de formación docente en algún lugar de este Uruguay. A ustedes les digo; bienvenidos/as a un sueño que ya es hoy. Ahí afuera hay un montón de niños, de niñas, de jóvenes que no siempre sabiendo que esperan, esperan. No alumnos, como categoría subjetiva institucional. Los que esperan son personas, los que esperan son presente y los esperan - a ustedes-, no como héroes y heroínas, los esperan humanas y humanos, con sus contradicciones y certezas, pero por sobre todo amorosamente sanas y sanos.

\section{Un posible comienzo}

Lo primero que debería decir en el marco de este texto que está naciendo es que hace ya mucho tiempo dejé de creer en la fortuna, en el azar o en la casualidad. Hace ya tiempo ubico lo que me acontece y lo que por allí acontece en el marco de lo inevitable, de lo que debe ocurrir, de lo que está pactado y de lo necesario.

Es claro que esta forma de ir concibiendo lo que por allí va ocurriendo puede ubicarse en concepciones espirituales o ancestrales o genealógicas, biogenéticas, culturales, mágicas, o donde quieran encontrar su razón. No obstante, no puedo ubicarme únicamente allí, pues existe un innumerable cuerpo de conocimientos teóricos, empíricos y filosóficos que se anticipan a lo que nos va ocurriendo cual profetización, pero no; es pura teoría, es puro análisis. Esta forma se encuentra en total armonía con cualquier explicación que integre la sabiduría de lo humano en tanto unidad, ya sea cuántica o espiritual. 
Lo que sí es cierto es que mi sesgo sociocultural, no mis experiencias -ellas son las que me hacen emerger una y otra vez- sino el conjunto de afectaciones ideológicas construidas sobre las experiencias de otros y otras, sobre un profundo ateísmo, sobre una profunda tensión puesta en la lucha de clases y en todo el conjunto de disputas binarias, todo eso forma parte de un enojo que aún me acompaña, porque ya también es mío. Todo eso me llevó a Freire, a su obra, y me llevó también a alejarme profundamente de él, tanto, que solo continuaron en mi viaje algunas ideas generales y populares (las más dichas y las más «ingenuas»), y otras entre líneas, quizás mucho más hermosas que aquellas.

Hace cien años nacía Freire, y este es el año de repensarlo o de pensarlo desde la inmensidad de nuevas experiencias, porque sería injusto pensar a Freire como si nada hubiese pasado. ¿Para qué recordarlo si nada aprendimos? ¿Para qué volver a decirlo de la misma forma en que se dijo?

También he «muerto», aunque muy pocos lo hayan notado. Morí de miedo, morí de tristeza, me ahogué, me fui ahogando una y otra vez; en mis palabras, en mis olvidos, en mis necesidades superfluas, en el reconocimiento, en mis emociones, en la victimización y en la soberbia me ahogué mil veces. Pero también renací una y otra vez, cada vez más hacia adentro, lo que, aunque no parezca, hace renacer también el afuera.

Créanme que quiero que lean esto que en breve ya no será mío, no quiero agotar a nadie, pero me parece importante hacerles saber que hoy me siento mucho más plural y fraternal, y por eso soy capaz de sentarme a contarles sobre Paulo Freire como si no lo conociese nadie.

El Paulo Freire que presento no tiene nada que ver con la lucha de clases, no tiene nada que ver con opresores, opresoras, oprimidos y oprimidas. No tiene nada que ver con la educación bancaria que siempre es la forma de educar de otros y otras, ajenos y ajenas, otredades en las cuales no nos reconocemos. O quizás sí algo que ver tenga, pero evidentemente jamás volvería a reducirlo a esa condición, a esa dualidad que insiste, que sigue operando como dominante de cierta forma de pensamiento que, en su anhelo de mejorar las condiciones de vida humana, ha persistido una y otra vez en creer que la base del cambio se encuentra en la apropiación de los mismos instrumentos que hemos referido como alienantes de nuestra propia humanidad. Ya sea a través de las luchas armadas y la conquista de los aparatos ideológicos y represivos, ya sea a través de las formas democráticas que en estas últimas dos décadas vivió nuestra América Latina; ya sea en una u otra forma, lo que queda claro es que eso que llamamos libertad e igualdad no se ha concretado, y quizás, solo desde esa perspectiva, ni siquiera esté en proceso. Por momentos me da la sensación de que las fuerzas tradicionales definidas como izquierda y derecha quedan reducidas a una cuestión cuantitativa de más o menos Estado de bienestar, y no duden de que en este mundo 
de hoy, de transiciones, creo en más que en menos Estado, pero es solo una creencia acotada de mi tiempo y es, además, un sueño que no he podido mejorar.

Dice Freire (1997) en relación con el proceso histórico de las sociedades:

Cuando comienzan a verse en sus propios ojos y se consideran capaces de proyectar, la desesperación de las sociedades alienadas pasa a ser sustituida por esperanza. Sucede esto cuando van interpretando los verdaderos deseos del pueblo. En la medida en que se van internando en su tiempo y en su espacio en el cual, críticamente, se descubren inacabados. Realmente no hay por qué desesperarse si se tiene la conciencia exacta, crítica de los problemas, de las dificultades y hasta de los peligros que se deben enfrentar. (p. 46).

No quiero desesperar en mi análisis porque pueda carecer de aceptación producto de cierta falta de cientificismo, no quiero desesperar si fuese a incurrir en algún error del tipo conceptual; de hecho, mis últimas lecturas sobre mis propias experiencias, que han ocurrido prácticamente entre individuos e instituciones, no me desalientan, aunque han sido percibidas como desaliento. Mi ficción es que encontremos en las formas ya dichas nuevas formas para decir. Plantear una suerte de antiecuación que nos permita zarpar hacia cualquier otra forma de anti-destino.

Cangi (2014) nos dirá en su referencia a Deleuze:

Intempestivo es aquel que no coincide con su tiempo ni se adecua a sus pretensiones. Es inactual, y por esta razón anacrónico para percibir el presente. No se trata de un gesto de nostalgia ni de odio porque sabe que no puede escapar a su tiempo, pero intuye que solo en una relación singular con éste es posible una percepción que insista y obre en desfasaje y anacronismo. Intempestivo es aquel que cree «lo Real llega de repente» como una prodigiosa bocanada de realidad en estado puro y afecta la percepción de los fenómenos. Es la diferencia entre la historia y el devenir que plantea Deleuze al alzarse intempestivo frente a la declaración de muerte de la filosofía. No se trata para él de ver la oscuridad del presente sino de percibir el acontecimiento que interpola el tiempo para transformar el porvenir. (p. 15)

Me siento un poco intempestivo, me he sentido siempre, pero ya no estoy tan enojado conmigo ni tengo mucho miedo, hasta estoy aprendiendo a callar y a hablar cuando se me pregunta, cuando alguien considera que mi voz puede entrar en juego con otras voces, y acá es donde empiezo a reencontrarme con Freire; veintitrés años después de mi primera relación educativa como educador, ya padre de un hijo y una hija grandes, y por lo menos quince años después de que, enojado conmigo, me alejé de Paulo.

Ayer volví a leerlo, en uno de los momentos más claros de mi devenir y más amorosos de mi transitar. Volví a leerlo en un reencuentro profundo con el pensamiento 
teórico, con las lecturas, y en un primer encuentro con estudiantes que anhelan ser maestras y maestros.

A ellos les presenté a Paulo Freire a través de sus Cartas a quien pretende enseñar, se los presenté sin tener la más pálida idea de su centenario, se los presenté porque mi curso es Pedagogía, y en la pedagogía latinoamericana no hay enojo ni ideología ni nada que pueda dejar a este hombre afuera.

Les presenté Cartas a quien pretende enseñar (Freire, 1993) porque consideré que era un texto amable y amoroso, y lo que quería era solo presentárselos, porque éticamente era imposible hacer otra cosa. Veinteañeras y veinteañeros nacidos en este siglo XXI avanzaron casi que por su propia cuenta cruzando la calle hacia su Pedagogía del oprimido (Freire, 2005). Ya no había vuelta atrás, Paulo les había llegado, estaba formando parte de lo que una vez llamé «comunidad». En paralelo, reencontrándome, reencontrándolo. Marcas precisas y comentarios a lo largo y ancho de cada uno de sus libros míos. Al derecho y al revés, a mí, veinteañero en aquel tiempo, Paulo también me había llegado.

Nadie se salva solo, ni nadie salva a nadie, los seres humanos se salvan juntos, en comunión

Resultaría imposible comprender la obra de Freire si no resultara posible comprender su amor profundo hacia la humanidad y su amor profundo a su Dios o a Dios o a Buda o al Gran Espíritu de los chamanes, la Naturaleza en lo Afro, o a quien sea; en definitiva, su amor a la unicidad, al todo que somos independientemente de la perspectiva del sueño. Es imposible comprenderlo sin aceptar su cristianismo y la particularidad teológica de su pensamiento. La teología liberadora constituye parte de su devenir.

La teología de la liberación comienza a tomar forma en la segunda mitad del siglo XX; nace en el contexto de la propia Iglesia y constituye una profunda reflexión «sobre el sentido mismo del cristianismo y sobre la misión de la iglesia» (Gutiérrez, 1972, p. 2).

Es una corriente del pensamiento cristiano y de la teología que busca conectar la acción evangelizadora con la lucha política ante la desigualdad social y económica. Denuncia la opresión y se compromete en la lucha social por la transformación, la justicia y la liberación popular. (Barboza, 2020, p. 56)

El pensamiento de Paulo Freire, es un pensamiento sobre las relaciones, todo el tiempo su referencia es a nosotros y los otros, todo es relación en las palabras de este hombre. Pero no la relación de los otros, sino nuestras propias relaciones, con nosotros, con los otros y con lo comunal. He aquí el punto que no había entendido, el punto que no podía ver antes. Me resistía porque mi propia alienación me impedía entonces comprenderlo. Siempre eran los otros quienes configuraban relaciones de poder des- 
igual etiquetadas o simplificadas en las categorías economicistas de patrón y obrero. Es posible que el límite de su tiempo, de su experiencia y de su lenguaje hiciesen acento en una suerte de relación oprimido-opresor en términos de clase, pero es imposible que la potencia de su pensamiento operase de manera reduccionista. Ese reduccionismo vino después, vino con nosotros, con nuestras experiencias, emociones y fragilidades, que tornaban imposible hacernos cargo de semejante contradicción. Entonces las relaciones opresivas quedaron reducidas a las relaciones de clase y la educación bancaria, a la que practicaban otros que nosotros veíamos y juzgábamos. La veía dentro de la escuela en otras compañeras y compañeros; la veía la educación no formal en la educación formal; los intelectuales burgueses de izquierda en las relaciones laborales; y así unos en otros y nunca en nosotros. Este límite es referido claramente por Rancière (2017): "Aventura individual suspendida en la imaginación de este extraño sueño colectivo: una civilización burguesa sin explotadores, una caballería sin señores, un dominio sin amos ni servidores, brevemente: la emancipación de los obreros" (p. 80).

Nosotros con capa de héroe y conciencia, generando conciencia, acompañando al otro en su liberación, en su concienciación, amorosamente, porque siempre hay mucho amor en esos intentos, aunque el no amor está en nosotras y nosotros. Más de diez años de adultez me llevaron a darme cuenta de que transitar una comunión real de seres humanos implica que uno a uno y juntos, cada día, sintamos que nos estamos salvando. Que nuestra salvación no está en que el otro "crezca» a nuestra medida, ni nuestra frustración cuando no sucede; eso que Paulo llama amor es el profundo respeto a uno mismo que automáticamente, en un no tiempo, se conforma en respeto hacia los demás. Félix Guattari (2000) hablaba de ecología individual, social y ambiental, que no es lo mismo pero es igual.

No tengo ni idea sobre de qué manera se está homenajeando por ahí a Paulo Freire, no he tenido tiempo aún y quiero disfrutar de lo que se diga, pero también quiero disfrutar de lo que tengo para compartir.

Lamento decirles que no existe posibilidad alguna de que una institución educativa instituya una educación para la libertad. No es posible, es incongruente, imposible; la historia de la educación, la historia de las relaciones educativas institucionalizadas, da cuenta de esto. Nadie educa para su muerte, la conciencia social de una época lo impide, pero la Modernidad ha sido capaz de desatender este punto y negar la unicidad de una forma diferente, velada, opaca. Partió de una diferencia centrada en la herencia y el trabajo, dejó caer la desigualdad de origen poniendo el acento en relaciones mercantiles y, por lo tanto, en la inversión de esas relaciones colocó también la transformación. Un gran sueño de etiqueta, que etiquetó una y otra vez, que construyó instituciones disciplinares para controlar y normalizar y que, al mismo tiempo, puso en esas instituciones el propio anhelo de libertad e igualdad. 
Dice Michel Foucault en diálogo con Noam Chomsky:

... una de las tareas que parece inmediata y urgente para mí, por encima de cualquier otra cosa, es esto: es la costumbre, al menos en nuestra sociedad europea, considerar que la potencia está localizada en manos del gobierno y que se ejerce a través de un cierto número de instituciones particulares como la administración, la policía y el ejército. Se sabe que todas estas instituciones están hechas para transmitir y aplicar órdenes y para castigar a aquellos que no obedecen. Pero creo que el poder político también se ejerce a través de la mediación de un cierto número de instituciones que parecen como si no tuviesen nada en común con el poder político y como si fueran independientes de eso, pero de hecho no lo son.

Uno conoce la universidad y más generalmente todos los sistemas de enseñanza que parecen diseminar conocimiento, están hechos para mantener una cierta clase social en el poder y para excluir los instrumentos de poder de otra clase social.

Me parece que la verdadera tarea política en nuestra sociedad contemporánea es criticar el funcionamiento de las instituciones - particularmente las que parecen ser neutrales e independientes - y atacarlas de tal manera en que la violencia política, que siempre se ha ejercido a través de ellas, finalmente queden desenmascaradas para que uno pueda luchar contra ellas. (Ernesto Oscar, 1971, minutos 38-44)

Si buscamos avanzar hacia otro modelo de sociedad "... sin haber criticado a fondo las relaciones entre las diferentes formas de violencia política que ejercen su poder dentro de nuestra sociedad, corremos el riesgo de dejar que se reproduzcan en cualquier modelo" (Ernesto Oscar, 1971, minutos 38-44).

$\mathrm{Ni}$ de cerca pretendo negar las desigualdades materiales, ni las laborales, ni las de oligarquía/pueblo, ni las de hombre/mujer; solo quiero decir que concentrarnos en relaciones duales constituye un reduccionismo, es la suma de todas estas relaciones y contradicciones lo que hoy planteamos a partir de una mirada freireana. Porque la primera alienación no es de uno hacia otros, sino la negación de nuestra propia condición de ser humano y de dignidad, y es interna, y quizás no debería definirse como contradicción sino como olvido o desconexión.

De una educación integral e integradora

Escribía Freire (1997):

Una educación que posibilite al hombre para la discusión valiente de su problemática, de su inserción en esa problemática, que lo advierta de los peligros de su tiempo para que, consciente de ellos, gane la fuerza y el valor para luchar, en lugar de ser arrastrado a la perdición de su propio «yo», sometido a las prescripciones ajenas. Educación que lo coloque en diálogo constante 
con el otro. Que lo predisponga a constantes revisiones y análisis críticos de sus «descubrimientos», a una cierta rebeldía en el sentido más humano de la expresión; que lo identifique, en fin, con métodos y procesos científicos. (Freire, p. 85)

Son muchos y muchas aquellos a quienes una y otra vez no pocas personas les han devuelto y agradecido aquella multiplicidad de encuentros; pequeños momentos y pequeñas cosas que, aunque ahí, tan dichas y tan presentes, constituían un no alcanza. Porque el mandato, el heroísmo y la transformación del otro solo podían ser vistos y reconocidos en un discurso de totalidad.

Los desafíos de nuestros tiempos no están en el futuro, producto de un sueño social que ya ni siquiera podemos soñar. Los desafíos de nuestro tiempo son construirnos en esos encuentros, son un aquí y ahora impostergable, son los descubrimientos de lo posible en las pequeñas cosas que van ocurriendo. Cabe, sí, añorar un mundo nuevo, pero lo cierto es que el más mundano de los mundos es este y es nuestro y ninguna adversidad o tiempo futuro podrá arrebatarlo. Las experiencias liberadoras son aquellas que, desde el más profundo amor, nos hacen sentir nuestro amor en nuestro pecho y que, para escuchar(nos), nos convocan al silencio.

La educación de Freire no es cronológica ni lineal en el tiempo. La educación de Freire es puro encuentro y es todo presente. La grandeza de la relación educativa reside en el amor del encuentro y sella un pacto de humanidad, de fraternidad, hace que nos amemos profundamente y que ya no podamos reconocernos sin esas presencias, o, quizás, dicho de otra forma, todas las presencias de nuestra vida son nuestra vida y son nuestra más bella y revolucionaria realidad.

\section{Un sueño sobre la educación democrática}

Freire nos habla de dejar entrar la vida y los acontecimientos. Nos habla de una discusión y un tratamiento valiente de nuestros problemas.

La democracia y la educación democrática se fundan en la creencia del hombre, en la creencia de que ellas no solo pueden sino que deben discutir sus problemas, el problema de su país, de su continente, del mundo; los problemas de su trabajo; los problemas de la propia democracia. (Freire, 1997, p. 92)

No importa el nivel educativo en el cual nos encontremos, siempre será bueno dejar entrar lo que cada estudiante trae y considera importante ofrecer(nos). Y en este marco de (re)conocimiento a quien nunca dispuso de una lectura fragmentada del mundo es que considero altamente pertinente hacer hablar a otros y otras. 
Dejar entrar lo que con cada uno/a de nosotros/as llega me hace pensar en aquel escolanovismo deweniano y, más cerca, en el planteamiento con potencia empírica aportada por la ciencia en los propios sistemas productivos del medio rural a través de la creación de escuelas-granja de Agustín Ferreiro. Y me hace pensar también en el pensamiento más cercano, pero no por eso estructuralmente diferente, de Corea y Lewkowicz (2004), quienes, mediante un profundo análisis de los dispositivos institucionales de la Modernidad, trazaron un conjunto de alteraciones discursivas de profunda deconstrucción y resignificación: "Pertenecer y estar dentro solo son sinónimos de la lógica del encierro; pertenecer al conjunto de los niños es estar encerrado en la escuela; pertenecer al conjunto de los trabajadores es estar encerrado en la fábrica" (p. 23).

En relación con la escuela, mucho está cuestionado desde su propio inicio y, al mismo tiempo, mucho de los cuestionamientos jamás fueron dirigidos a su propia forma. Los maestros y maestras, educadores/as, hemos puesto el acento en su dependencia de lo que hemos definido como clases dominantes, y parecería que, en ese acento como aparato ideológico, basta con su apropiación para que la misma institución con la misma forma de disposición de tiempos y espacios, con el mismo énfasis en la repetición, con la misma despersonalización de siempre, responda a otros intereses y ya no los dominantes.

Hoy, llegando al primer cuarto del siglo XXI, el desastre ecosófico planteado por el SARS-CoV-2 alteró formas de funcionamiento social, con un énfasis sostenido y permanente en una nueva forma de relacionamiento humano centrada, primero que nada, en la distancia como sinónimo de salud.

En términos de educación, se dispuso el cierre de los edificios y paulatinamente se fue buscando la manera de —a través de dispositivos tecnológicos informáticosmantener todos los aspectos posibles de la propia forma escolar. Obviamente que eso se redujo a contenidos y tiempo. También nos dimos cuenta de que se necesitaba un espacio y nos dimos cuenta de que las ausencias de estos elementos conformaban las ausencias de esos otros y otras en la educación virtual. Pero hasta aquí quizás solo como aspectos de la propia externalidad, porque lo que vimos también fue la baja significatividad que para muchos poseen las instituciones educativas $y$, por sobre todo, en referencia a la posibilidad de encuentro.

¿Qué deberían ser las instituciones educativas sino lugares de encuentro, de construcción de vida común y comunal? He aquí un sentido profundo de la visión de Freire sobre la educación. La educación es palabra y es voz, es medio y mediadora, es constructora de sentido, pero nuestros sistemas continúan siendo contenidistas y hoy queda claro que, si el eje ha de ser ese contenidismo, no importa si la educación es virtual o presencial y mucho menos importa si se necesita una escuela. Al respecto, cabe mencionar que hacia el año 2017 en Uruguay se creó un Marco Curricular de Referencia Nacional (ANEP-CODICEN, 2017) que intenta trascender el mero conte- 
nidismo hacia macro-habilidades para la vida y, asimismo, busca pensar la relación educativa en términos de trayectorias de los y las estudiantes. Es un buen intento de cambio de matriz que ni cerca está de anclar en los cuerpos docentes. Este aspecto se debe a ciertas premisas que son el producto de una ficción corporativa y no de la realidad de aquellos últimos:

Los estudiantes, en cuanto ciudadanos, tienen derecho a un legado cultural, lo cual implica centrarse en sus aprendizajes. Esto conlleva valorar la enseñanza como provocadora y mediadora de aprendizajes significativos. Cobra relevancia la acción educativa del docente como intelectual transformador que desarrolla una práctica grupal en múltiples contextos culturales que le exige potenciar su pensamiento crítico para viabilizar cambios pertinentes. (ANEP-CODICEN, 2017, p. 31).

Si esta es una premisa que se considera necesaria, entonces no constituye una premisa, en tanto ese punto de partida dista de la realidad. Luego, si ese ha de ser una condición necesaria a construir, entonces no basta con su enunciación y he aquí la necesidad de recuperar el legado histórico de nuestras relaciones educativas en sus diferentes niveles y articularlo a la luz de aspectos que ya no pueden seguir siendo negados: a) los docentes no pueden seguir dedicando cuarenta horas reloj semanales al trabajo directo; b) el modelo de cuatro horas debe ser revisado, existen experiencias como las escuelas y centros de media de tiempo extendido que deben ser adecuadas a la totalidad del sistema educativo; c) debe darse por finalizado el enciclopedismo por lo menos hasta finalizar tercer año de educación media básica; d) el trabajo intelectual de los docentes una vez finalizada su formación profesional primaria no puede estar sujeto ni a la discrecionalidad del educador o educadora ni bajo la órbita de los subsistemas, es necesario que forme parte de un cuerpo externo a ellos pero con funcionamiento interno dentro de los establecimientos educativos, ya que solo allí se producirá la relación práctica-teoría.

\section{De nuestras propias contradicciones}

No importa la institución en la cual desarrollemos nuestra actividad educativa, leamos atentamente la siguiente cita y simplemente pensemos en nuestras prácticas y otras que por allí vemos. No es polisémica la idea que plantea Freire y de ahí que no existan muchas posibilidades de sentirse allí o no. Mas cualquier intento de forzar nuestra entrada ha de constituir una omisión que se expresa en nuestros cuerpos físicos y en nuestra propia intimidad.

Dictamos clases. No debatimos o discutimos temas. Trabajamos sobre el educando. No trabajamos con él. Le imponemos un orden que él no comparte, al cual sólo se acomoda. No le ofrecemos medios para pensar auténticamente, porque al recibir las fórmulas dadas simplemente las guarda. No las incorpora, porque la incorporación es el resultado de la búsqueda de algo que exige, de 
quien lo intenta, un esfuerzo de recreación y de estudio. Exige reinvención. (Freire, 1997, p. 93)

No vamos a totalizar las prácticas ni cerca ni lejos de aquel sueño, solo insistimos en que nos pensemos a partir él.

\section{Sobre la condición política del diálogo}

Extrañamente, pese al aparente pesimismo de esta última idea, pese a que no lo parezca, tramitado el enojo y el miedo ya referido en este artículo, hoy más que nunca veo una humanidad que quiere cambiar, y no la veo ciertamente en una posibilidad futura, sino en el aquí y ahora de niños y niñas, y la veo en el aquí y ahora de muchas compañeras y compañeros educadores.

Entre el residuo que hoy son las instituciones de la Modernidad, entre el agobio, la exresistencia y el conjunto de los posibles futuros producto de los ismos totalizadores, entre todo eso veo educadoras y educadores construyendo presente, haciendo explotar de alegría y pensamiento sus aulas, y cualquier espacio es ocupado para fijar allí un presente de relaciones, donde el diálogo atraviesa los cuerpos para construir un único cuadro sin marco, un mapa inédito para ellos, un rizoma sin principio ni final.

Ver estudiantes asomar sus cabezas enfrentando sus biografías y las imposibilidades de superar el conservadurismo ya caduco de las instituciones disciplinares, y ver docentes trazar mil fugas que se invitan a navegar; ver confluir esas valentías, verlas dibujarse entre voces, silencios y formas, ver(se) en esos presentes solo nos dice que siempre es el momento justo para hacer lo que creemos y podemos hacer.

Veamos a Freire (1997) en ello:

«Del momento en que hablamos al educando al momento en que hablamos con él»; o: «de la necesidad de hablarle al educando a la necesidad de hablar con él». Esto quiere decir que hay momentos en los que la maestra, como autoridad, le habla al educando, dice lo que debe ser hecho, establece límites sin los cuales la propia libertad del educando se pierde en la permisividad, pero estos momentos se alternan, según la opción política de la educadora, con otros en los que la educadora habla con el educando. (p. 94).

\section{Maestra sí, tía no. La dimensión política de la educadora y el educador}

Falsamente, en el marco de la dualidad del pensamiento, de nuestras necesidades y de nuestras propias ficciones totalizadoras, quizás concretadas en la forma en las cuales han venido transitando nuestras propias organizaciones sindicales, hemos ido construyendo una idea de lo nuestro y una idea de lo otro, alcanzando la pertenencia a ese nosotros masa para encontrar en el afuera la otredad y una suerte de no recono- 
cimiento. Lo cierto es que la realidad es mucho más hermosa cuando podemos verla sin lentes de ajenidad.

Lo nuestro por momentos adquiere el componente electoralista más complejo, en el cual la premisa opera en los individuos y no en la claridad de lo que unos y otros representan. Las ansias, las motivaciones personales, las ambiciones nos hacen jugar en una lucha extremadamente desigual entre sueños de ser mejores y la permanente insistencia, tanto de hombres como de mujeres, de afirmarse y mantener el modelo patriarcal.

La política, cuando se constituye en patriarcal, no busca sueños colectivos de ser mejores, solo busca centrarse en liderazgos, ya sea en forma de mamá o de papá.

El concepto de liderazgo se da por hecho e incluso hasta quienes introducen la idea de sostenibilidad se limitan a realizar una distinción entre ciertas formas de liderazgo no beneficiosas para los desarrollos que buscan llevar adelante y otras formas diferentes, más favorables a esos cambios propuestos. La forma de abordar el concepto de líder queda ligada a las formas del ejercicio del liderazgo, a su externalidad, pero no a las relaciones humanas, que pueden llegar a significar formas relacionales que configuran la existencia de unos en un lugar del mapa social y la de otros en otro.

Guattari -que en la obra citada nos introduce también en las formas de la dominación y otras aún no construidas o en construcción o habitadas y deshabitadas - nos dice: «Ahora bien, aquí ya no puede tratarse de consignas estereotipadas, reduccionistas, que eliminen otras problemáticas más singulares y que implican la promoción de líderes carismáticos» (1990, p. 19, citado en Barboza, 2020, p. 37)

Las perpetuaciones de las relaciones de dependencia se ven reforzadas por una suerte de entrega sumisa hacia un otro que se constituye en padre o en líder. Esta puede ser comprendida, entonces, como otro de los componentes capilares de la dominación, que queda asociada a las formas vinculares patriarcales que aquí se definen como toda forma de ejercicio desigual del poder. (Barboza, 2020, p. 39)

En la dimensión política del educador, Freire invita al posicionamiento coherente, al saberse crítica y conscientemente en un sitio; luego, toda su obra gira en torno a la autoconcienciación y la autoliberación, que no es tanto ni únicamente individual, sino con otras y otros, en comunión.

No está por demás repetir aquí la afirmación, todavía rechazada por mucha gente no obstante su obviedad. La educación es un acto político. Su no neutralidad exige de la educadora que asuma su identidad política y viva coherentemente su opción progresista, democrática o autoritaria, reaccionaria, aferrada a un pasado; o bien espontaneísta, que se defina por ser democrática 
o autoritaria. Es que el espontaneísmo, que a veces da la impresión que se inclina por la libertad, acaba trabajando contra ella. (Freire, 1997, p. 94)

Por último, y en este juego de pensarnos en las palabras de Freire, pero no en las palabras vaciadas por polisemia, sino en su pensamiento oscilante entre el concepto duro y la belleza de su propio relato, invito a todas las educadoras y educadores a repensarse a la luz de lo que nos sigue diciendo:

Lo ideal será cuando sin importar cuál sea la política de la administración, ya sea progresista o reaccionaria, las maestras se definan siempre como maestras. Lo lamentable es que oscilen entre ser tías de buen comportamiento en las administraciones autoritarias y maestras rebeldes en las administraciones democráticas. Mi esperanza es que experimentándose libremente en administraciones abiertas acaben por incorporar el gusto por la libertad, por el riesgo de crear, y se vayan preparando para asumirse plenamente como maestras, como profesionales, entre cuyos deberes está el de testimoniar a sus alumnos y a las familias de los alumnos, el de rechazar su arrogancia, pero con dignidad y energía, el arbitrio y el todopoderosísimo de ciertos administradores llamados modernos. (Freire, 1997, p. 12)

Muchas gracias a Paulo Freire, muchas gracias a quienes han impulsado este reconocimiento en sus cien años y muchas gracias a la infinidad de educadoras y educadores que día a día buscan, a través de las diversas formas del amor, construir relaciones educativas que, partiendo de disminuir el inevitable daño generado por las instituciones, habilitan un presente, un aquí y ahora que ya nadie les podrá arrebatar.

\section{Referencias bibliográficas}

ANEP-CODICEN (2017). Marco Curricular de Referencia Nacional. Una construcción colectiva. https://mcrn.anep.edu.uy/sites/default/files/Documento\%20MCRN\%20 agosto\%202017.pdf

Barboza, D. (2020). Leerse para ser mejor: un análisis organizacional para un proceso sostenible de mejora. Trabajo final de Maestría en Gestión Educativa-Universidad ORT Uruguay, inédito.

Cangi, A. (2014). Deleuze: una introducción. Quadrata.

Corea, C. y Lewkowicz, I. (2004). Pedagogía del aburrido. Paidós Educador.

Dewey, J. (1995). Democracia y educación. Morata.

Freire, P. (1969 [1997]). La educación como práctica de la libertad. Siglo XXI.

Freire, P. (1993). Cartas a quien pretende enseñar. Siglo XXI Editores.

Freire, P. (2005). Pedagogía del oprimido. Siglo XXI Editores.

Pino, R. (1988). Tradición y actualidad en el pensamiento pedagógico de Agustín Ferreiro. ANEP-CEP.

Ranciere, J. (2017). La noche de los proletarios: archivos del sueño obrero. Tinta Limón Ediciones. 
Material audiovisual de referencia

Ernesto Oscar. (1971). Debate Michel Foucault Noam Chomsk subtitulado al español. Amara Public (Free). https://www.youtube.com/watch?v=OxU17CC4XVM 